\title{
Cyclosporin A-Induced Hyperlipidemia
}

\author{
Maaike Kockx and Leonard Kritharides
}

Additional information is available at the end of the chapter

http://dx.doi.org/10.5772/47866

\section{Introduction}

Cyclosporin A (CsA) is an immunosuppressant drug widely used in organ transplant recipients and patients with auto-immune disorders. Long-term treatment with CsA is associated with hyperlipidemia and an increased risk of atherosclerosis. The mechanisms by which cyclosporin A causes hyperlipidemia are unclear. Cell and animal studies have pointed to various mechanisms that may mediate CsA-induced hyperlipidemia. In this review we will give an overview of CsA-induced hyperlipidemia, with a focus on the data available that might explain the underlying mechanism(s) and describe the available treatment regimes used to treat hyperlipidemia induced by immunosuppressant drugs.

\section{Hyperlipidemia in humans after solid organ transplantation}

Hyperlipidemia is observed in about $60 \%$ of kidney, liver, cardiac and bone marrow transplants after treatment with CsA (for review see [1,2]. There are multiple factors potentially contributing to hyperlipidemia in these patients, such as post-transplantation obesity, multiple drug therapy and diabetes. The concurrent use of steroids in particular, makes it hard to establish a direct contribution of CsA to dyslipidemia in humans, as corticosteroids are known to exacerbate hyperlipidemia in transplant recipients $[3,4]$.

Studies investigating plasma lipids after CsA monotherapy are limited $[4,5,6,7,8,9]$ and only a few studies have directly compared the combination of CsA therapy with low dose prednisolone with other immune suppressing strategies in combination with low dose steroids $[10,11]$. In general, these studies indicate that CsA treatment can independently lead to elevated plasma triglyceride and cholesterol levels in humans and that these effects are reversible upon cessation of immunosuppression therapy (Table 1). Animal studies (reviewed in [12]), where the effect of CsA can be studied in a more controlled background, indicate that CsA directly raises plasma lipid levels in rats, mice, guinea pigs and rabbits, and have proven that animals are valuable models to study mechanisms of CsA-induced hyperlipidemia. 
Lipoproteins - Role in Health and Diseases

\begin{tabular}{|c|c|c|c|c|c|}
\hline Treatment & Patients & $\begin{array}{l}\text { Patient } \\
\text { number }\end{array}$ & Duration & Lipid effects & Reference \\
\hline Monotherapy & $\begin{array}{l}\text { Amyotrophic } \\
\text { lateral } \\
\text { sclerosis }\end{array}$ & 36 & 2 mnths & $\begin{array}{l}\text { TC } \uparrow(21 \%) \\
\text { LDL-C } \uparrow(31 \%) \\
\text { apoB }(12 \%) \\
\text { TG }= \\
\text { HDL }=\end{array}$ & [5] \\
\hline Monotherapy & $\begin{array}{l}\text { Autologous } \\
\text { bone marrow } \\
\text { transplants }\end{array}$ & 13 & 32 days & $\begin{array}{l}\text { TC }(26 \%) \\
\text { LDL-C } \uparrow \\
\text { HDL-C } \downarrow \\
\text { TG }= \\
\text { VLDL-C }=\end{array}$ & [13] \\
\hline Monotherapy & $\begin{array}{l}\text { Renal } \\
\text { transplants }\end{array}$ & 59 & $\begin{array}{l}\text { 3-6 and } 12 \\
\text { mnths }\end{array}$ & $\begin{array}{l}\text { TC }= \\
\text { LDL-C }= \\
\text { apoB } \uparrow \\
\text { TG } \uparrow \\
\text { HDL-C } \downarrow \\
\text { apoA-I } \downarrow\end{array}$ & [8] \\
\hline Monotherapy & $\begin{array}{l}\text { Renal } \\
\text { transplants }\end{array}$ & 58 & $>1 \mathrm{yr}$ & $\begin{array}{l}\text { TC } \\
\text { LDL-C } \\
\text { apoB } \uparrow \\
\text { TG } \uparrow \\
\text { VLDL-C = } \\
\text { HDL-C } \downarrow \\
\text { HDL2-C = } \\
\text { HDL3-C } \downarrow\end{array}$ & [14] \\
\hline $\begin{array}{l}\text { Monotherapy } \\
\text { and CsA/pred }\end{array}$ & $\begin{array}{l}\text { Bone marrow } \\
\text { transplants }\end{array}$ & 180 & 100 days & $\begin{array}{l}\text { TC } \uparrow \\
\text { LDL-C } \uparrow \\
\text { apoB } \uparrow \\
\text { TG } \uparrow \\
\text { VLDL-trig } \uparrow \\
\text { VLDL-C = } \\
\text { HDL } \downarrow \\
\text { HDL2 } \downarrow \\
\text { HDL3 = } \\
\text { apoA-I } \downarrow\end{array}$ & {$[4]$} \\
\hline Monotherapy & Psoriasis & 15 & 3 mnths & $\begin{array}{l}\text { TC } \uparrow(22 \%) \\
\text { LDL-C } \uparrow(35 \%) \\
\text { TG }= \\
\text { VLDL-C = } \\
\text { HDL-C = }\end{array}$ & [9] \\
\hline
\end{tabular}




\begin{tabular}{|c|c|c|c|c|c|}
\hline Treatment & Patients & $\begin{array}{l}\text { Patient } \\
\text { number }\end{array}$ & Duration & Lipid effects & Reference \\
\hline $\begin{array}{l}\text { ALG/aza/cort v } \\
\text { CsA/ALG/aza/cort }\end{array}$ & $\begin{array}{l}\text { Renal } \\
\text { transplants }\end{array}$ & 702 & 52 wks & $\begin{array}{l}\text { TC } \uparrow(20 \%) \\
\text { LDL-C } \\
\text { TG } \uparrow \\
\text { HDL-C }=\end{array}$ & [7] \\
\hline $\begin{array}{l}\text { Aza/pred v CsA v } \\
\text { CsA/pred }\end{array}$ & $\begin{array}{l}\text { Renal } \\
\text { transplants }\end{array}$ & 9 & 3 mnths & $\begin{array}{l}\text { TC } \uparrow \\
\text { LDL-C } \uparrow(45 \%) \\
\text { TG }= \\
\text { VLDL-C = } \\
\text { HDL-C = }\end{array}$ & [6] \\
\hline $\begin{array}{l}\text { Aza/pred v } \\
\text { CsA/pred }\end{array}$ & $\begin{array}{l}\text { Renal } \\
\text { transplants }\end{array}$ & 20 & 7.7 yrs & $\begin{array}{l}\text { TC } \uparrow \\
\text { LDL-C } \\
\text { apoB } \uparrow \\
\text { TG } \uparrow \\
\text { VLDL-C } \uparrow \\
\text { HDL-C } \downarrow\end{array}$ & [10] \\
\hline
\end{tabular}

ALG, Minnesota antilymphocyte globulin; aza, azathioprine; cort, corticosteroids; pred, prednisolone TC, total cholesterol; TG, total triglyceride; LDL, low density lipoprotein; VLDL, very low density lipoprotein; HDL, high density lipoprotein; apo, apolipoprotein;

Table 1. Effect of CsA on plasma lipid parameters in humans

\subsection{Plasma VLDL}

Triglyceride-containing VLDL particles are produced in the liver via lipidation of apolipoprotein B (apoB) by microsomal triglyceride transfer protein (MTP), generating triglyceride-poor (VLDL2) as well as triglyceride-rich VLDL (VLDL1) particles, both of which can be secreted [15]. In plasma, VLDL is converted to intermediate-density lipoprotein (IDL) by lipoprotein lipase (LPL). IDL can be further hydrolyzed by lipases to low density lipoprotein (LDL). CsA increases plasma VLDL levels in transplant recipients and a concomitant increase in plasma apoB levels is observed [4,10,11]. It is unclear whether both plasma VLDL1 and VLDL2 levels are elevated. In contrast to LDL levels, plasma triglyceride and VLDL levels appear to increase only after long-term treatment with CsA (Table 1 and [8])

Hypertriglyceridemia in transplant patients is associated with increased plasma apolipoprotein CIII (apoCIII) levels $[16,17,18]$ and decreased lipase activity (see below). As apoCIII inhibits LPL and hepatic lipase (HL) as well as uptake of triglyceride lipoprotein in liver, the increase of apoCIII may be an important contributor to hypertriglyceridemia found in transplant patients.

\subsection{Plasma LDL}

Plasma LDL levels appear to be consistently elevated by CsA $[4,5,6,7,9,10,13,14]$ even in patients where plasma VLDL levels are not altered $[5,6,9,13]$. A correlation between CsA 
levels and plasma LDL-C has been described in some studies [19], but was not observed in others [5,20]. Regulation of plasma LDL levels is complex, depending on hepatic VLDL production, subsequent lipolysis of VLDL, clearance of LDL via the LDL receptor (LDLr) in the liver and conversion into bile. CsA may affect LDL metabolism at several levels (section 3.2).

\subsection{Plasma HDL}

Total plasma HDL levels are inversely correlated with the risk of cardiovascular disease [21]. HDL particles are however heterogeneous in size and composition, and occur as HDL2a, HDL2b, HDL3a, HDL3b and HDL3c which are progressively smaller in diameter and contain higher protein to lipid ratios. The precise contribution of various HDL subclasses to cardiovascular disease is currently unclear [21,22]. Plasma HDL cholesterol levels are determined by production of nascent HDL particles in the liver and intestine, by plasma transfer reactions of lipids between HDL and lipolysed triglyceride lipoproteins such as VLDL or chylomicrons, hepatic uptake of HDL lipids via the scavenger receptor class B1 (SRB1) HDL receptor in the liver, and renal clearance of small, lipid-poor apoA-I particles. Nascent HDL particles are formed by lipidation of apolipoprotein A-I (apoA-I) via the ATP-binding cassette transporter-1 (ABCA1) located in cellular membranes, although ABCA1-independent pathways of apoA-I lipidation also exist [23]. The formed lipid-poor HDL particles acquire more lipid after interaction with ABCG1 and mature by the subsequent esterification of cholesterol by lecithin-acyl transferase (LCAT). Further remodeling occurs by phospholipid transfer protein (PLTP) generating HDL2. HDL2 can be converted into HDL3 by hydrolysis via lipases and by transfer of cholesteryl esters to triglyceride-containing lipoproteins with the reciprocal exchange for triglycerides, which is mediated by cholesteryl ester transfer protein (CETP).

Immunosuppressive therapy has been reported to increase, decrease or leave HDL levels unaffected [5,10,11,24]. Parallel changes in plasma apoA-I levels are usually observed. Increased HDL levels are observed in most transplant patients, but this is most likely related to the concomitant treatment with steroids, which are known to increase plasma HDL [3]. CsA may affect particular subclasses of HDL more than others. Independently of steroids, plasma HDL levels, especially the HDL3 subpopulation, were found to inversely relate to plasma CsA levels [19]. In a study of bone marrow transplant recipients CsA decreased total plasma HDL, and in particular HDL2 [4]. In rats, a similar decrease in plasma HDL and HDL2 levels was observed after CsA treatment [25]. A recent study performed in pediatric renal transplant recipients showed that although total plasma HDL levels were not changed with CsA treatment, the relative proportion of HDL2b decreased while the relative proportion of HDL3a, HDL3b and HDL3c increased [26]. This is important as decreased HLD2b with increased HDL3b is associated with an atherogenic lipoprotein phenotype characterized by increased triglycerides and small dense LDL [27]. This result also emphases that simple monitoring of total HDL cholesterol may be insufficient to understand the consequences of CsA on HDL biology. 


\subsection{Plasma lipoprotein (a)}

Lipoprotein (a) [Lp(a)] is a LDL-like lipoprotein consisting of LDL with one molecule of apoB covalently linked to a molecule of apolipoprotein (a). Plasma Lp(a) levels, and especially certain genetic $L p(a)$ variants, are independently associated with an increased risk for CVD [28,29]. Elevated Lp(a) plasma levels have been observed in renal transplant studies $[14,30]$ this was however, not observed by others [31]. Although some studies suggested normalization of elevated Lp(a) levels after successful transplantation due to improved kidney function [31,32], CsA treatment has been indicated to independently increase Lp(a) levels in renal transplant recipients $[8,14,33]$. The mechanisms by which CsA affect plasma $\mathrm{Lp}$ (a) levels are unexplored, but may involve similar mechanisms to that of elevation of plasma LDL levels. As the LDLr does not play a major role in the clearance of Lp(a), the mechanism however, is unlikely mediated via effects of CsA on the LDLr (see section 3.2.1).

\subsection{Qualitative differences in lipoproteins}

\subsubsection{Particle changes}

Elevated plasma triglyceride levels are associated with the formation of triglyceride rich LDL particles that are more atherogenic [34]. A high prevalence of smaller denser LDL particles is observed in transplant recipients [35] and appears to be associated with CsA therapy [26,36]. Inhibition of lipoprotein lipase (LPL) activity is associated with the formation of small dense LDL subclasses. As apoCIII inhibits lipase activity, increased plasma apoCIII levels observed with CsA-treatment may explain inhibited lipase activity and subsequent increase in small dense LDL particles [17]. In addition decreased lipase activity could contribute to decreased HDL2 subclasses observed, while effects on CETP by CsA may help explain increases in HDL3 subfractions (see section 2.3 and 3.1.2).

\subsubsection{Interaction of CsA with plasma lipoproteins}

In whole blood CsA is primarily transported bound to lipoproteins (33\%) and erythrocytes (58\%) and whole blood CsA levels correlate with lipoprotein levels [37,38]. In vitro and in vivo studies show that in serum from healthy patients $50-60 \%$ of CsA is bound to HDL, 20$30 \%$ to LDL, $10-25 \%$ to VLDL with $10-15 \%$ bound to the non-lipoprotein proteins $[39,40,41,42]$. However, the proportion of CsA bound to the LDL and VLDL fractions increases in hyperlipidemic serum, without changing the amount bound to free protein $[40,41]$, indicating that the distribution of CsA between the lipoprotein classes will change as plasma lipoprotein concentrations change. The binding of CsA to lipoprotein particles may also depend on lipoprotein composition. For example, Wasan et al. [41] showed that high triglyceride content of HDL was associated with a decreased percentage of CsA recovered in the HDL fraction and an increased percentage recovered in the VLDL fraction. Interestingly, treatment of patients with lipid lowering agents, such as statins have been reported to increase the unbound fraction of CsA and clearance of CsA in plasma [43].

Concerns have been raised about changes to the bioavailabilty and activity of CsA resulting from its binding to lipoproteins, especially as decreased CsA activity and increased toxicity 
have been observed in patients with hyperlipidemia [42,44]. CsA levels are higher in hyperlipidemic patients due to decreased clearance which was reversed after lipid-lowering with fibrates (reviewed in [37]). In vitro studies using skin fibroblasts indicate that CsA bound to LDL does not affect binding to cells via the LDLr, but uptake of CsA is inhibited [45]. These studies were confirmed in HepG2 and Jurkat Tcells which showed decreased uptake of CsA in the presence of LDL [40]. In line with these findings, uptake of CsA in tissues from rats was reduced when CsA was co-injected with lipoproteins [46].

\section{Mechanisms of CsA-Induced hyperlipidemia - What we learn from cell and animal studies}

As the effects of CsA in humans are confounded by many factors such as other medication, obesity, insulin resistance and nutritional status, cell and animal studies are useful to elucidate the mechanism(s) of CsA-induced hyperlipidemia. Figure 1 depicts the reported CsA-effects on VLDL, LDL and HDL metabolism.

\subsection{VLDL}

\subsubsection{Effects of CsA on VLDL synthesis and secretion}

CsA decreased apoB translocation over the endoplasmic reticulum (ER) membrane in the human liver cell line HepG2 [47]. It was suggested that this was due to a reduction in the efficiency of lipid transfer by inhibition of MTP, however whether MTP activity is inhibited by CsA was not investigated. These findings are in line with the report from Kaptein et al. [48], which showed that CsA inhibits VLDL and apoB secretion from HepG2 cells, by posttranslational mechanisms. In contrast, in mice, CsA increased the rate of hepatic VLDL secretion in vivo, while total apoB secretion was unaffected [49]. No effect of CsA on levels of VLDL receptors in either adipose tissue or skeletal muscle were found [50] suggesting that VLDL uptake may not be affected by CsA. There are no studies that we are aware of studying the effect of CsA on in vivo VLDL synthesis in humans.

\subsubsection{VLDL metabolism}

Inhibition of lipolysis by CsA could contribute to increased plasma VLDL and reduced HDL concentrations. Various studies have investigated lipase activity in patients, but results may be confounded by co-treatment with steroids. HL activity was increased in cardiac transplant patients and correlated with CsA dose while lipoprotein lipase (LPL) activity was decreased in these patients [51]. Others have shown decreased HL as well as LPL activity in kidney transplant recipients [52]. More directly, Tory et al [53] showed suppression of LPL activity in plasma from normolipidemic subjects treated with CsA, while in rats, CsA doseand time-dependent decreased plasma LPL activity [24]. In addition, LPL abundance in skeletal muscle and adipose tissue was decreased in rats [50]. These latter studies suggested CsA can inhibit LPL activity independently of steroids. Although the precise mechanism of CsA-inhibited LPL activity is unknown, it helps to explain increased triglyceride levels observed after CsA treatment. 
Some studies show reduced cholesteryl ester transfer protein (CETP) activity in transplant recipients [54]. In contrast, CsA directly added to human plasma ex vivo increased CETP activity [53]. These apparently anomalous results may relate to differences between the direct effects of CsA on CETP itself and indirect effects secondary to changes in the concentrations of other lipoproteins, but remain unexplained. Since CETP transfers cholesteryl ester from HDL to apoB-containing lipoproteins with reciprocal transfer of triglycerides, any effect of CsA on CETP activity could be expected to have major effects on plasma lipoprotein profiles.

\subsection{LDL}

\subsubsection{LDL synthesis and catabolism}

We have recently reviewed this literature in detail [55]. There appear to be conflicting conclusions arising from in vitro and in vivo studies. One of the key discrepancies is the role of LDLr expression and LDL clearance by the liver in mediating CsA-hyperlipidemia. In general, in vitro studies are consistent with a role for decreased LDL receptor expression or activity in liver cells after exposure to CsA [48,56]. In vivo studies however, show mixed effects, with no effect or an increase in hepatic LDLr protein or mRNA levels $[49,50]$. Similarly 3-hydroxy-3-methyl-glutaryl-CoA reductase (HMG-CoAr), the rate limiting enzyme in cholesterol synthesis, mRNA levels were upregulated in HepG2 cells and mouse liver after CsA, but hepatic HMG-CoA reductase protein levels in rat liver were unaffected by CsA treatment $[49,50,57]$. In rats, CsA decreased the fractional catabolic rate of LDL [58]. One very important consideration is the difference in concentrations of CsA used in in vitro studies relative to those achieved in vivo under normal transplant immunosuppression. In vitro studies commonly use concentrations of $10 \mu \mathrm{g} / \mathrm{ml}$ whereas plasma levels of CsA in humans and in animal studies are typically in the order of $100 \mathrm{ng} / \mathrm{ml}$. This apparent 10-fold difference in concentration may underestimate the difference in effective concentrations tested in vivo and in vitro studies because of the complicating effects of in vivo hyperlipidemia, which under some circumstances can lessen the effective concentration of CsA delivered to some tissues [46].

\subsection{HDL}

CsA effects on plasma HDL and HDL subclasses may be mediated by effects on the synthesis and/or formation of HDL as well as by effecting remodeling of HDL through changes in lipase and/or CETP activity (see 3.1.2)

\subsubsection{Effect of CsA on HDL synthesis and formation}

In vitro studies have indicated that CsA potently inhibits ABCA1 activity thereby inhibiting apoA-I lipidation, the first step in HDL formation [59,60,61]. This was associated with decreased ABCA1 turnover and an increase in total and cell-surface levels of ABCA1 [59]. Uptake, Internalization and re-secreton of apoA-I were however decreased by CsA, 
suggesting that ABCA1 trapped at the plasma membrane is dysfunctional $[59,60]$. In vivo studies using wild type C57Bl6 mice corroborated these in vitro findings. CsA lowered plasma HDL levels after 6 days of treatment [59]. A lowering in plasma HDL in mice was however not observed by others after long-term treatment of mice with CsA combined with a high fat diet [62]. As many aspects of lipid metabolism can be affected by CsA, it may be difficult to determine a causal effect on HDL levels via ABCA1 inhibition in an in vivo whole body system NB.

Direct effects of CsA on the expression of ABCA1 and apoA-I have also been reported and may contribute to the changes in HDL formation. The target of immunosuppression by CsA, Nuclear Factor of activated T-cells, cytoplasmic 2 (NFATc2), was found to bind the mouse ABCA1 promoter and mediate CsA-inhibition of ABCA1 expression by inflammatory stimuli [63]. In addition CsA has been found to inhibit apoA-I gene expression in human HepG2 cells and rats [64]. A recent proteomic study in HepG2 cells showed that CsA decreased secretion levels of apoA-I suggesting that the transcriptional effects of CsA on apoA-I expression may lead to decreased amounts of secreted apoA-I [65].

\subsubsection{Effects on HDL metabolism}

As mentioned above (section 3.1.2), CsA directly suppresses LPL activity and increases CETP activity in human plasma and animals (section 3.1.2). LPL activity is strongly associated with plasma HDL2 concentrations [66], and decreased LPL levels in CsA treatment may therefore contribute to decreased HDL2 levels [4,25]. On the other hand, increased CETP activity will generate triglyceride-rich HDL, which is converted to smaller HDL3 particles by HL [66].

\subsection{Effects on bile acid synthesis and secretion}

\subsubsection{Effects on bile synthesis}

In liver, cholesterol is converted to bile acids by $7 \alpha$-hydroxylase (CYP7 $\alpha$ ) or 27-hydroxylase (CYP27A1) [67]. In healthy humans, CYP7 $\alpha$ is considered the predominantly pathway while CYP27A1 accounts for $10 \%$ of bile acid synthesis and subsequent formation of chenodeoxycholate. However inhibition of Cyp7 $\alpha$ can increase the contribution of the CYP27A1 pathway [68]. In vitro studies show that CsA inhibits both CYP27A1 activity and subsequent formation of chenodeoxycholate in human and animal liver extracts and in primary hepatocyte cultures [57,69,70,71]. A CsA responsive element has been mapped on the CYP27A1 promoter [72], indicating that CsA affects transcription of the CYP27A1 gene directly. In most of the in vitro studies, CYP7 $\alpha$ activity was not affected by CsA $[69,70]$. In vivo, in rat however, CsA decreased CYP7 $\alpha$ protein levels [50], indicating that the predominant bile acid synthesis pathway may also be affected by CsA. The inhibitory effect of CsA on bile synthesis is suggested to contribute to increased plasma lipid concentrations in transplant recipients. Radioisotope studies performed in children after liver transplantation demonstrated that CsA treatment significantly inhibits bile salts synthesis 
rates, especially that of chenodeoxycholate and that bile acid synthesis rate inversely correlates with plasma cholesterol and triglyceride levels [73].

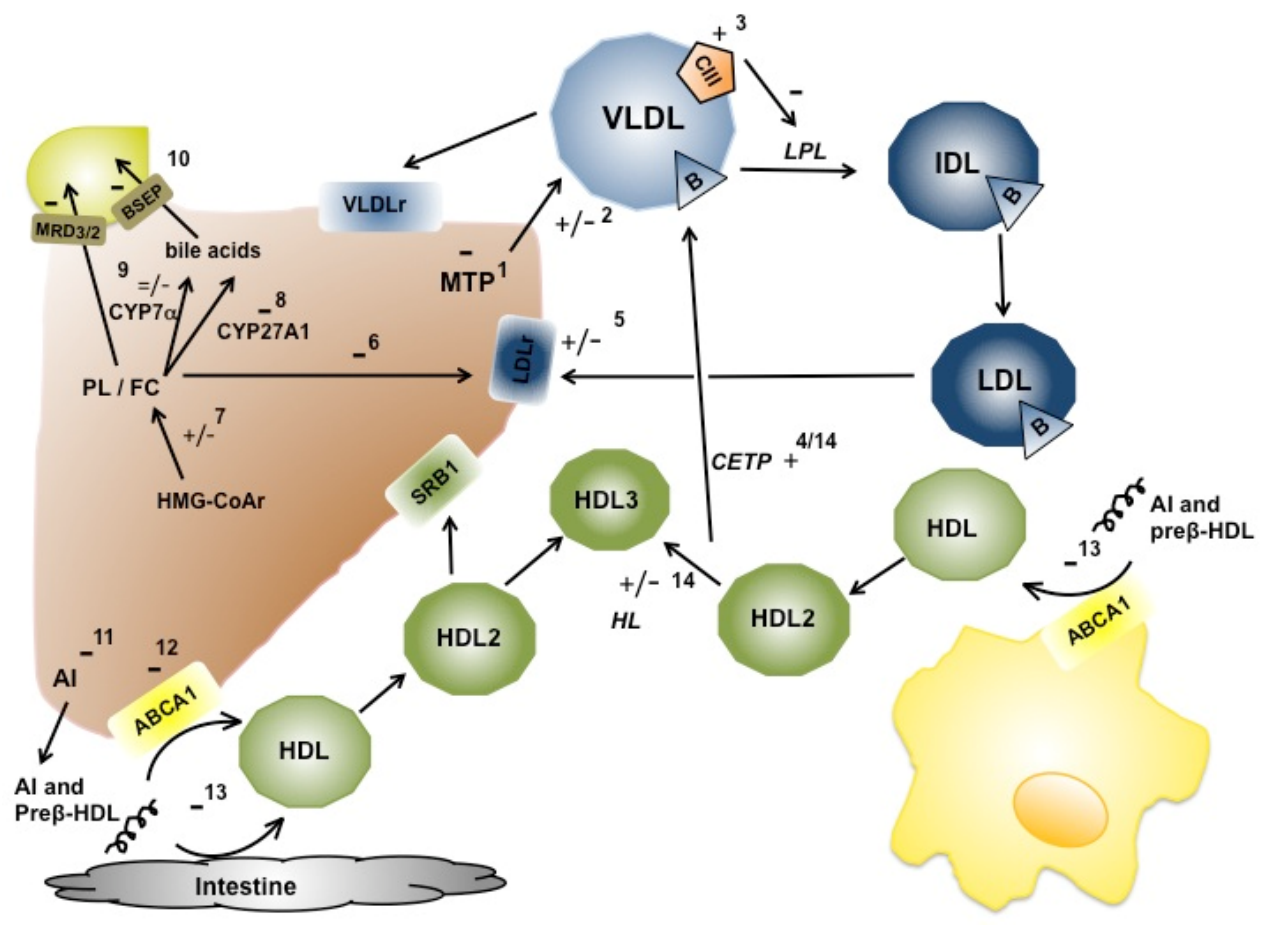

Figure 1. Mechanisms of CsA-mediated hyperlipidemia. Figure only displays pathways that are reported to be affected by CsA. 1) Inhibition of VLDL formation via inhibition of MTP, 2) Increased and decreased secretion of VLDL particles have been reported, 3) Decreased lipolysis of VLDL due to increased apoCIII and subsequent inhibition of LPL, 4) hypertriglyceridemia by increased CETP activity, 5) Increased LDL due to decreased LDLr expression as well as activity, 6) Increased liver FC content leading to decreased LDLr levels, 7) Increased and decreased levels of HMG-CoAr affecting cholesterol synthesis, 8/9) Inhibition of bile acid conversion via CYP27A1 or CYP7 $\alpha$ leading to increased liver FC levels, however in most studies Cyp7 $\alpha$ is not affected by CsA. NB: decreased CYP27A1 activity can increase HMG-CoAr levels via negative feedback, 10) Decreased flow of bile salts, cholesterol and phospholipids into bile, 11) Decreased expression and secretion of apoA-I, 12) Inhibition of ABCA1 expression, 13) inhibition of apoA-I lipidation via inhibition of ABCA1 activity 14) Stimulation of HL and CETP leads to increased formation of HDL2 to HDL3, however decreased HL activity has also been reported. VLDL, very low density lipoprotein; IDL, intermediate density lipoprotein; LDL, low density lipoprotein; HDL, high density lipoprotein; AI, apolipoprotein A-I, B, apolipoprotein B; CIII, apolipoprotein CIII; MTP, microsomal triglyceride transfer protein; LPL, lipoprotein lipase; HL, hepatic lipase; CETP, cholesteryl ester transfer protein; ABCA1, ATP-binding cassette transporter-1; SRB1, scavenger receptor class B1; LDLr, LDLreceptor; VLDLr, VLDLreceptor; PL, phospholipid; FC, free cholesterol; HMG-CoAr, 3-hydroxy-3-methyl-glutaryl-CoA reductase; CYP7 $\alpha, 7 \alpha$-hydroxylase; CYP27A1, 27-hydroxylase; MRD, multidrug resistance protein; BSEP, bile salt export protein. 
The effects of CsA on CYP27A1 may relate to effects of CsA on cholesterol metabolism. 27hydroxycholesterol is a potent negative feedback regulator of HMG-CoA reductase [74] and decreased CYP27A1 activity may therefore explain increased HMG-CoA reductase mRNA and cholesterol levels [57]. Although important in macrophages, it should be noted however that it is not clear whether such a feedback loop exists in liver cells [75]. Increased cholesterol synthesis could subsequently lead to downregulation of LDLr levels as observed in some CsA studies, also contributing to increased plasma cholesterol levels (see section 3.2.1).

Besides effects on bile acid synthesis CsA may affect bile flow. CsA treatment is associated with increased plasma bile acid concentrations and cholestasis in humans as well as in animal models $[9,52,76]$. Studies in rat indicate that bile flow and the secretion of bile salts, proteins and lipids into the bile are dose-dependently inhibited by CsA [52,76,77]. Interestingly, the changes in serum levels of bile acids are consistent with CsA-mediated inhibition of hepatocellular uptake of individual bile acids $[78,79]$. The inhibitory effect was greater for phosholipid secretion than that for cholesterol [80] and in some studies no inhibition of cholesterol excretion was observed [81], suggesting differential effects on transport mechanisms. Transport pumps involved in bile synthesis and secretion belong to the family of the ATP-binding cassette transporters which include, multidrug resistance proteins (MDR) and P-glycoprotein, and most of which are effectively inhibited by CsA [79,82]. Interestingly, comparison of the bile salt export pump (BSEP) activity from different species, showed that CsA inhibits bile salt transport with species and bile salt specific variation [83]. Rat BSEP was for example more effectively inhibited than mouse BSEP. Biliary cholesterol secretion is mediated via ABCG5 and ABCG8 [84]. Although both members of the ATPbinding cassette family, it has not been investigated whether CsA inhibits ABCG5/8 activity. As phospholipids are transported via MDR3, it is likely that differences in efficacy of CsA between inhibition of MRD3 and ABCG5/8 exist. It is clear that CsA can affect bile flow and secretion in cultured cells and animal models. It should be noted however, that in humans no inhibitory effect of CsA on secretion of bile acids and lipids or on bile composition after liver transplantation was observed [85]. Others have shown that although cholate synthesis was reduced by CsA, compensatory increased intestinal absorption counteracted this decrease [86]. It remains therefore unclear to what extent inhibition of bile flow and secretion by CsA are contributing to hypercholesteremia in vivo.

\section{Therapies to address hyperlipidemia}

Hyperlipidemia is associated with significant morbidity and mortality rates in transplant recipients [87]. Many strategies have been investigated to target dyslipidemia in transplant patients. A number of excellent comprehensive reviews have been published on the clinical management of hyperlipidemia and its risks (eg [88,89]). We will therefore restrict our comments to a very brief summary of this area.

\subsection{Statins}

Statins inhibit HMG-CoA reductase, the rate limiting enzyme in the cholesterol synthesis pathway and are world-wide the drug of choice to lower plasma LDL-C levels. Various 
statins have been tested in transplant patients and all show significant lowering of plasma cholesterol, LDL-C and apoB levels with some indicating improved survival rates (for review see $[88,89,90])$. A randomized trial, investigating the safety and efficacy of statins in renal transplant patients, the Assessment of LEscol in Renal Transplantation (ALERT) study, showed that fluvastatin effectively lowered LDL-C by $32 \%$ and reduced cardiac death and non-fatal myocardial infarction incidence significantly [91]. Importantly, statins may provide beneficial effects other then their lipid-lowering properties [92]. Wissing et al [93] reported improved flow mediated brachial artery vasodilatation by atorvastatin in kidney transplant patients and significant reductions in acute rejections have been observed in cardiac transplant patients [94].

Rhabdomyolysis, one of the few serious side effects of statins, is more common with high dose statin treatment. The risk is elevated in patients with renal disease and in patients taking drugs affecting statin metabolism, especaily in those taking CsA [88,89]. All statins have the potential to interact with CsA, as CsA substantially increases plasma levels of all statins. Although this is most notable for those metabolized via the Cyp3A4 pathway, statins not metabolized via the Cyp3A4 pathway [95] such as pravastatin and fluvastatin are also affected [95], suggesting that the interaction of CsA and statins may involve other mechanisms such as inhibition of drug transporters. Simvastatin poses the highest risk of myopathy, and particular care must be taken with higher doses of this agent, with recommendations that doses of $10 \mathrm{mg} / \mathrm{d}$ are not exceeded in transplant patients [89]. Because statin therapy has been associated with mortality benefit after transplantation, correction of hyperlipidemia using lower doses of statins is mandatory after transplantation. Therefore careful clinical monitoring of patients as well as measurement of creatine kinase levels to detect muscle injury is advised, and the use of statins that are not metabolized via CYP3A4, such as fluvastatin or pravastatin may be preferential [95].

\subsection{Fibrates}

Fibrates lower plasma triglyceride levels via activation of the Peroxisome Proliferator Activated Receptor alpha (PPAR $\alpha$ ) and may be useful in transplant patients with elevated plasma triglycerides especially in combination with statin treatment to lower plasma cholesterol levels. Gemfibrozil was found to significantly lower plasma triglyceride levels in heart transplant patients and increase long term survival [96,97]. Fenofibrate is less well studied in transplant patients and may be associated with increased nephrotoxicity $[88,98]$. Care must be taken administering fibrates with CsA, particularly in combination with statins as drug-drug interactions exist via CYP3A4 as well as the hepatic uptake transporter the organic anion transporting polypeptide 1B1 (OAT1B1).

\subsection{Ezetimibe}

Inhibition of intestinal cholesterol absorption to lower high plasma cholesterol levels may be used when statins or fibrates are ineffective or are not tolerated. Ezetimibe proved to be an effective drug lowering plasma LDL-C levels significantly by blocking cholesterol 
absorption in the small intestine [99]. To that point though, various studies showed effective LDL-C lowering in liver, cardiac and renal transplant recipients [99]. Although, drug-drug interaction between CsA and ezetimibe were suggested (See [88]), CsA levels in studied transplant patients were not affected by combined ezetimibe use (reviewed in [99]). Coadministration of ezetimibe with (low-dose) statins has been found to effectively reduce high plasma cholesterol levels in transplant recipients and may be useful in patients that resistant to high-dose statin or where target plasma lipid levels can not be achieved by statin therapy alone [100,101].

\section{Conclusions}

CsA-induced hyperlipidemia is well established and remains a significant clinical issue. CsA potentially affects many aspects of lipid and lipoprotein metabolism and the precise underlying mechanism(s) causing dyslipidemia are still unclear. Further mechanistic studies may lead to the generation immunosuppressants that do not cause hyperlipidemia or may help to develop strategies to effectively target CsA-induced hyperlipidemia.

\section{Author details}

Maaike Kockx

Macrophage Biology Group, Centre for Vascular Research, University of New South Wales, Sydney, Australia

Leonard Kritharides*

Macrophage Biology Group, Centre for Vascular Research, University of New South Wales, Sydney, Australia

Department of Cardiology, Concord Repatriation General Hospital, University of Sydney, Sydney, Australia

\section{References}

[1] Kobashigawa JA, Kasiske BL (1997) Hyperlipidemia in solid organ transplantation. Transplantation 63: 331-338.

[2] Miller LW (2002) Cardiovascular toxicities of immunosuppressive agents. Am J Transplant 2: 807-818.

[3] Strohmayer EA, Krakoff LR (2011) Glucocorticoids and cardiovascular risk factors. Endocrinol Metab Clin North Am 40: 409-417, ix.

[4] Lopez-Miranda J, Perez-Jimenez F, Torres A, Espino-Montoro A, Gomez P, et al. (1992) Effect of cyclosporin on plasma lipoproteins in bone marrow transplantation patients. Clin Biochem 25: 379-386.

[5] Ballantyne CM, Podet EJ, Patsch WP, Harati Y, Appel V, et al. (1989) Effects of cyclosporine therapy on plasma lipoprotein levels. JAMA 262: 53-56.

${ }^{*}$ Corresponding Author 
[6] Raine AE, Carter R, Mann JI, Morris PJ (1988) Adverse effect of cyclosporin on plasma cholesterol in renal transplant recipients. Nephrol Dial Transplant 3: 458-463.

[7] Kasiske BL, Tortorice KL, Heim-Duthoy KL, Awni WM, Rao KV (1991) The adverse impact of cyclosporine on serum lipids in renal transplant recipients. Am J Kidney Dis 17: 700-707.

[8] Hilbrands LB, Demacker PN, Hoitsma AJ, Stalenhoef AF, Koene RA (1995) The effects of cyclosporine and prednisone on serum lipid and (apo)lipoprotein levels in renal transplant recipients. J Am Soc Nephrol 5: 2073-2081.

[9] Edwards BD, Bhatnagar D, Mackness MI, Gokal R, Ballardie FW, et al. (1995) Effect of low-dose cyclosporin on plasma lipoproteins and markers of cholestasis in patients with psoriasis. QJM 88: 109-113.

[10] Schorn TF, Kliem V, Bojanovski M, Bojanovski D, Repp H, et al. (1991) Impact of longterm immunosuppression with cyclosporin A on serum lipids in stable renal transplant recipients. Transpl Int 4: 92-95.

[11] Ichimaru N, Takahara S, Kokado Y, Wang JD, Hatori M, et al. (2001) Changes in lipid metabolism and effect of simvastatin in renal transplant recipients induced by cyclosporine or tacrolimus. Atherosclerosis 158: 417-423.

[12] Kockx M, Guo DL, Traini M, Gaus K, Kay J, et al. (2009) Cyclosporin A decreases apolipoprotein $\mathrm{E}$ secretion from human macrophages via a protein phosphatase 2Bdependent and ATP-binding cassette transporter A1 (ABCA1)-independent pathway. J Biol Chem 284: 24144-24154.

[13] Luke DR, Beck JE, Vadiei K, Yousefpour M, LeMaistre CF, et al. (1990) Longitudinal study of cyclosporine and lipids in patients undergoing bone marrow transplantation. J Clin Pharmacol 30: 163-169.

[14] Brown JH, Anwar N, Short CD, Bhatnager D, Mackness MI, et al. (1993) Serum lipoprotein (a) in renal transplant recipients receiving cyclosporin monotherapy. Nephrol Dial Transplant 8: 863-867.

[15] Adiels M, Olofsson SO, Taskinen MR, Boren J (2008) Overproduction of very lowdensity lipoproteins is the hallmark of the dyslipidemia in the metabolic syndrome. Arterioscler Thromb Vasc Biol 28: 1225-1236.

[16] Kimak E, Solski J, Baranowicz-Gaszczyk I, Ksiazek A (2006) A long-term study of dyslipidemia and dyslipoproteinemia in stable post-renal transplant patients. Ren Fail 28: 483-486.

[17] Badiou S, Garrigue V, Dupuy AM, Chong G, Cristol JP, et al. (2006) Small dense lowdensity lipoprotein in renal transplant recipients: a potential target for prevention of cardiovascular complications? Transplant Proc 38: 2314-2316.

[18] Tur MD, Garrigue V, Vela C, Dupuy AM, Descomps B, et al. (2000) Apolipoprotein CIII is upregulated by anticalcineurins and rapamycin: implications in transplantationinduced dyslipidemia. Transplant Proc 32: 2783-2784.

[19] Kuster GM, Drexel H, Bleisch JA, Rentsch K, Pei P, et al. (1994) Relation of cyclosporine blood levels to adverse effects on lipoproteins. Transplantation 57: 1479-1483.

[20] Ramezani M, Einollahi B, Ahmadzad-Asl M, Nafar M, Pourfarziani V, et al. (2007) Hyperlipidemia after renal transplantation and its relation to graft and patient survival. Transplant Proc 39: 1044-1047. 
[21] Kontush A, Chapman MJ (2006) Functionally defective high-density lipoprotein: a new therapeutic target at the crossroads of dyslipidemia, inflammation, and atherosclerosis. Pharmacol Rev 58: 342-374.

[22] Rosenson RS, Brewer HB, Jr., Chapman MJ, Fazio S, Hussain MM, et al. (2011) HDL measures, particle heterogeneity, proposed nomenclature, and relation to atherosclerotic cardiovascular events. Clin Chem 57: 392-410.

[23] Zheng H, Kiss RS, Franklin V, Wang MD, Haidar B, et al. (2005) ApoA-I lipidation in primary mouse hepatocytes. Separate controls for phospholipid and cholesterol transfers. J Biol Chem 280: 21612-21621.

[24] Lopez-Miranda J, Perez-Jimenez F, Gomez-Gerique JA, Espino-Montoro A, HidalgoRojas L, et al. (1992) Effect of cyclosporin on plasma lipoprotein lipase activity in rats. Clin Biochem 25: 387-394.

[25] Espino A, Lopez-Miranda J, Blanco-Cerrada J, Zambrana JL, Aumente MA, et al. (1995) The effect of cyclosporine and methylprednisolone on plasma lipoprotein levels in rats. J Lab Clin Med 125: 222-227.

[26] Zeljkovic A, Vekic J, Spasojevic-Kalimanovska V, Jelic-Ivanovic Z, Peco-Antic A, et al. (2011) Characteristics of low-density and high-density lipoprotein subclasses in pediatric renal transplant recipients. Transpl Int 24: 1094-1102.

[27] Berneis KK, Krauss RM (2002) Metabolic origins and clinical significance of LDL heterogeneity. J Lipid Res 43: 1363-1379.

[28] Erqou S, Kaptoge S, Perry PL, Di Angelantonio E, Thompson A, et al. (2009) Lipoprotein(a) concentration and the risk of coronary heart disease, stroke, and nonvascular mortality. JAMA 302: 412-423.

[29] Clarke R, Peden JF, Hopewell JC, Kyriakou T, Goel A, et al. (2009) Genetic variants associated with Lp(a) lipoprotein level and coronary disease. N Engl J Med 361: 25182528 .

[30] Fonseca I, Queiros J, Costa S, Santos MJ, Henriques AC, et al. (2002) Lipoprotein(A) in renal transplant recipients. Transplant Proc 34: 370-372.

[31] Innocenti M, Lorenzetti M, Naldi F, Paleologo G, Pasquariello A, et al. (1998) Evaluation of lipoprotein A in renal transplant recipients. Transplant Proc 30: 2048.

[32] Black IW, Wilcken DE (1992) Decreases in apolipoprotein(a) after renal transplantation: implications for lipoprotein(a) metabolism. Clin Chem 38: 353-357.

[33] Webb AT, Reaveley DA, O'Donnell M, O'Connor B, Seed M, et al. (1993) Does cyclosporin increase lipoprotein(a) concentrations in renal transplant recipients? Lancet 341: 268-270.

[34] Packard CJ, Shepherd J (1997) Lipoprotein heterogeneity and apolipoprotein B metabolism. Arterioscler Thromb Vasc Biol 17: 3542-3556.

[35] Rajman I, Harper L, McPake D, Kendall MJ, Wheeler DC (1998) Low-density lipoprotein subfraction profiles in chronic renal failure. Nephrol Dial Transplant 13: 2281-2287.

[36] Quaschning T, Mainka T, Nauck M, Rump LC, Wanner C, et al. (1999) Immunosuppression enhances atherogenicity of lipid profile after transplantation. Kidney Int Suppl 71: S235-237. 
[37] Akhlaghi F, Trull AK (2002) Distribution of cyclosporin in organ transplant recipients. Clin Pharmacokinet 41: 615-637.

[38] Gardier AM, Mathe D, Guedeney X, Barre J, Benvenutti C, et al. (1993) Effects of plasma lipid levels on blood distribution and pharmacokinetics of cyclosporin A. Ther Drug Monit 15: 274-280.

[39] Sgoutas D, MacMahon W, Love A, Jerkunica I (1986) Interaction of cyclosporin A with human lipoproteins. J Pharm Pharmacol 38: 583-588.

[40] Rifai N, Chao FF, Pham Q, Thiessen J, Soldin SJ (1996) The role of lipoproteins in the transport and uptake of cyclosporine and dihydro-tacrolimus into HepG2 and JURKAT cell lines. Clin Biochem 29: 149-155.

[41] Wasan KM, Pritchard PH, Ramaswamy M, Wong W, Donnachie EM, et al. (1997) Differences in lipoprotein lipid concentration and composition modify the plasma distribution of cyclosporine. Pharm Res 14: 1613-1620.

[42] De Klippel N, Sennesael J, Lamote J, Ebinger G, de Keyser J (1992) Cyclosporin leukoencephalopathy induced by intravenous lipid solution. Lancet 339: 1114.

[43] Akhlaghi F, McLachlan AJ, Keogh AM, Brown KF (1997) Effect of simvastatin on cyclosporine unbound fraction and apparent blood clearance in heart transplant recipients. Br J Clin Pharmacol 44: 537-542.

[44] de Groen PC, Aksamit AJ, Rakela J, Forbes GS, Krom RA (1987) Central nervous system toxicity after liver transplantation. The role of cyclosporine and cholesterol. N Engl J Med 317: 861-866.

[45] Wasan KM, Ramaswamy M, Kwong M, Boulanger KD (2002) Role of plasma lipoproteins in modifying the toxic effects of water-insoluble drugs: studies with cyclosporine A. AAPS PharmSci 4: E30.

[46] Lemaire M, Pardridge WM, Chaudhuri G (1988) Influence of blood components on the tissue uptake indices of cyclosporin in rats. J Pharmacol Exp Ther 244: 740-743.

[47] Macri J, Adeli K (1997) Studies on intracellular translocation of apolipoprotein B in a permeabilized HepG2 system. J Biol Chem 272: 7328-7337.

[48] Kaptein A, de Wit EC, Princen HM (1994) Cotranslational inhibition of apoB-100 synthesis by cyclosporin $\mathrm{A}$ in the human hepatoma cell line HepG2. Arterioscler Thromb 14: 780-789.

[49] Wu J, Zhu YH, Patel SB (1999) Cyclosporin-induced dyslipoproteinemia is associated with selective activation of SREBP-2. Am J Physiol 277: E1087-1094.

[50] Vaziri ND, Liang K, Azad H (2000) Effect of cyclosporine on HMG-CoA reductase, cholesterol 7alpha-hydroxylase, LDL receptor, HDL receptor, VLDL receptor, and lipoprotein lipase expressions. J Pharmacol Exp Ther 294: 778-783.

[51] Superko HR, Haskell WL, Di Ricco CD (1990) Lipoprotein and hepatic lipase activity and high-density lipoprotein subclasses after cardiac transplantation. Am J Cardiol 66: 1131-1134.

[52] Deters M, Kirchner G, Koal T, Resch K, Kaever V (2004) Everolimus/cyclosporine interactions on bile flow and biliary excretion of bile salts and cholesterol in rats. Dig Dis Sci 49: 30-37. 
[53] Tory R, Sachs-Barrable K, Hill JS, Wasan KM (2008) Cyclosporine A and Rapamycin induce in vitro cholesteryl ester transfer protein activity, and suppress lipoprotein lipase activity in human plasma. Int J Pharm 358: 219-223.

[54] Atger V, Leclerc T, Cambillau M, Guillemain R, Marti C, et al. (1993) Elevated high density lipoprotein concentrations in heart transplant recipients are related to impaired plasma cholesteryl ester transfer and hepatic lipase activity. Atherosclerosis 103: 29-41.

[55] Kockx M, Jessup W, Kritharides L (2010) Cyclosporin A and atherosclerosis--cellular pathways in atherogenesis. Pharmacol Ther 128: 106-118.

[56] Rayyes OA, Wallmark A, Floren CH (1996) Cyclosporine inhibits catabolism of lowdensity lipoproteins in HepG2 cells by about 25\%. Hepatology 24: 613-619.

[57] Gueguen Y, Ferrari L, Souidi M, Batt AM, Lutton C, et al. (2007) Compared effect of immunosuppressive drugs cyclosporine $\mathrm{A}$ and rapamycin on cholesterol homeostasis key enzymes CYP27A1 and HMG-CoA reductase. Basic Clin Pharmacol Toxicol 100: 392-397.

[58] Lopez-Miranda J, Vilella E, Perez-Jimenez F, Espino A, Jimenez-Pereperez JA, et al. (1993) Low-density lipoprotein metabolism in rats treated with cyclosporine. Metabolism 42: 678-683.

[59] Le Goff W, Peng DQ, Settle M, Brubaker G, Morton RE, et al. (2004) Cyclosporin A traps ABCA1 at the plasma membrane and inhibits ABCA1-mediated lipid efflux to apolipoprotein A-I. Arterioscler Thromb Vasc Biol 24: 2155-2161.

[60] Lorenzi I, von Eckardstein A, Cavelier C, Radosavljevic S, Rohrer L (2008) Apolipoprotein A-I but not high-density lipoproteins are internalised by RAW macrophages: roles of ATP-binding cassette transporter A1 and scavenger receptor BI. J Mol Med 86: 171-183.

[61] Karwatsky J, Ma L, Dong F, Zha X (2009) Cholesterol efflux to apoA-I in ABCA1expressing cells is regulated by Ca2+ dependent-calcineurin signaling. J Lipid Res.

[62] Emeson EE, Shen ML (1993) Accelerated atherosclerosis in hyperlipidemic C57BL/6 mice treated with cyclosporin A. Am J Pathol 142: 1906-1915.

[63] Maitra U, Parks JS, Li L (2009) An innate immunity signaling process suppresses macrophage ABCA1 expression through IRAK-1-mediated downregulation of retinoic acid receptor alpha and NFATc2. Mol Cell Biol 29: 5989-5997.

[64] Zheng XL, Wong NC (2006) Cyclosporin A inhibits apolipoprotein AI gene expression. J Mol Endocrinol 37: 367-373.

[65] Van Summeren A, Renes J, Bouwman FG, Noben JP, van Delft JH, et al. (2011) Proteomics investigations of drug-induced hepatotoxicity in HepG2 cells. Toxicol Sci 120: 109-122.

[66] von Eckardstein A, Huang Y, Assmann G (1994) Physiological role and clinical relevance of high-density lipoprotein subclasses. Curr Opin Lipidol 5: 404-416.

[67] Anderson KE, Kok E, Javitt NB (1972) Bile acid synthesis in man: metabolism of 7 hydroxycholesterol- $14 \mathrm{C}$ and 26-hydroxycholesterol- $3 \mathrm{H}$. J Clin Invest 51: 112-117.

[68] Duane WC, Javitt NB (1999) 27-hydroxycholesterol: production rates in normal human subjects. J Lipid Res 40: 1194-1199. 
[69] Souidi M, Parquet M, Ferezou J, Lutton C (1999) Modulation of cholesterol 7alphahydroxylase and sterol 27-hydroxylase activities by steroids and physiological conditions in hamster. Life Sci 64: 1585-1593.

[70] Princen HM, Meijer P, Wolthers BG, Vonk RJ, Kuipers F (1991) Cyclosporin A blocks bile acid synthesis in cultured hepatocytes by specific inhibition of chenodeoxycholic acid synthesis. Biochem J 275 ( Pt 2): 501-505.

[71] Winegar DA, Salisbury JA, Sundseth SS, Hawke RL (1996) Effects of cyclosporin on cholesterol 27-hydroxylation and LDL receptor activity in HepG2 cells. J Lipid Res 37: 179-191.

[72] Segev H, Honigman A, Rosen H, Leitersdorf E (2001) Transcriptional regulation of the human sterol 27-hydroxylase gene (CYP27) and promoter mapping. Atherosclerosis 156: 339-347.

[73] Hulzebos CV, Bijleveld CM, Stellaard F, Kuipers F, Fidler V, et al. (2004) Cyclosporine A-induced reduction of bile salt synthesis associated with increased plasma lipids in children after liver transplantation. Liver Transpl 10: 872-880.

[74] Esterman AL, Baum H, Javitt NB, Darlington GJ (1983) 26-hydroxycholesterol: regulation of hydroxymethylglutaryl-CoA reductase activity in Chinese hamster ovary cell culture. J Lipid Res 24: 1304-1309.

[75] Javitt NB (2002) 25R,26-Hydroxycholesterol revisited: synthesis, metabolism, and biologic roles. J Lipid Res 43: 665-670.

[76] Stone BG, Udani M, Sanghvi A, Warty V, Plocki K, et al. (1987) Cyclosporin A-induced cholestasis. The mechanism in a rat model. Gastroenterology 93: 344-351.

[77] Roman ID, Monte MJ, Gonzalez-Buitrago JM, Esteller A, Jimenez R (1990) Inhibition of hepatocytary vesicular transport by cyclosporin $\mathrm{A}$ in the rat: relationship with cholestasis and hyperbilirubinemia. Hepatology 12: 83-91.

[78] Azer SA, Stacey NH (1994) Differential effects of cyclosporin A on transport of bile acids by rat hepatocytes: relationship to individual serum bile acid levels. Toxicol Appl Pharmacol 124: 302-309.

[79] Stieger B, Fattinger K, Madon J, Kullak-Ublick GA, Meier PJ (2000) Drug- and estrogeninduced cholestasis through inhibition of the hepatocellular bile salt export pump (Bsep) of rat liver. Gastroenterology 118: 422-430.

[80] Galan AI, Roman ID, Munoz ME, Cava F, Gonzalez-Buitrago JM, et al. (1992) Inhibition of biliary lipid and protein secretion by cyclosporine A in the rat. Biochem Pharmacol 44: 1105-1113.

[81] Chan FK, Shaffer EA (1997) Cholestatic effects of cyclosporine in the rat. Transplantation 63: 1574-1578.

[82] Bohme M, Jedlitschky G, Leier I, Buchler M, Keppler D (1994) ATP-dependent export pumps and their inhibition by cyclosporins. Adv Enzyme Regul 34: 371-380.

[83] Kis E, Ioja E, Nagy T, Szente L, Heredi-Szabo K, et al. (2009) Effect of membrane cholesterol on BSEP/Bsep activity: species specificity studies for substrates and inhibitors. Drug Metab Dispos 37: 1878-1886.

[84] Yu L, Gupta S, Xu F, Liverman AD, Moschetta A, et al. (2005) Expression of ABCG5 and ABCG8 is required for regulation of biliary cholesterol secretion. J Biol Chem 280: 87428747. 
[85] Baiocchi L, Angelico M, De Luca L, Ombres D, Anselmo A, et al. (2006) Cyclosporine A versus tacrolimus monotherapy. Comparison on bile lipids in the first 3 months after liver transplant in humans. Transpl Int 19: 389-395.

[86] Hulzebos CV, Wolters H, Plosch T, Kramer W, Stengelin S, et al. (2003) Cyclosporin a and enterohepatic circulation of bile salts in rats: decreased cholate synthesis but increased intestinal reabsorption. J Pharmacol Exp Ther 304: 356-363.

[87] Toussaint C, Kinnaert P, Vereerstraeten P (1988) Late mortality and morbidity five to eighteen years after kidney transplantation. Transplantation 45: 554-558.

[88] Bilchick KC, Henrikson CA, Skojec D, Kasper EK, Blumenthal RS (2004) Treatment of hyperlipidemia in cardiac transplant recipients. Am Heart J 148: 200-210.

[89] Ballantyne CM, Corsini A, Davidson MH, Holdaas H, Jacobson TA, et al. (2003) Risk for myopathy with statin therapy in high-risk patients. Arch Intern Med 163: 553-564.

[90] Ojo AO (2006) Cardiovascular complications after renal transplantation and their prevention. Transplantation 82: 603-611.

[91] Holdaas H, Fellstrom B, Jardine AG, Holme I, Nyberg G, et al. (2003) Effect of fluvastatin on cardiac outcomes in renal transplant recipients: a multicentre, randomised, placebo-controlled trial. Lancet 361: 2024-2031.

[92] Blum A, Shamburek R (2009) The pleiotropic effects of statins on endothelial function, vascular inflammation, immunomodulation and thrombogenesis. Atherosclerosis 203: 325-330.

[93] Wissing KM, Unger P, Ghisdal L, Broeders N, Berkenboom G, et al. (2006) Effect of atorvastatin therapy and conversion to tacrolimus on hypercholesterolemia and endothelial dysfunction after renal transplantation. Transplantation 82: 771-778.

[94] Kobashigawa JA, Katznelson S, Laks H, Johnson JA, Yeatman L, et al. (1995) Effect of pravastatin on outcomes after cardiac transplantation. N Engl J Med 333: 621-627.

[95] Asberg A (2003) Interactions between cyclosporin and lipid-lowering drugs: implications for organ transplant recipients. Drugs 63: 367-378.

[96] Pflugfelder PW, Huff M, Oskalns R, Rudas L, Kostuk WJ (1995) Cholesterol-lowering therapy after heart transplantation: a 12-month randomized trial. J Heart Lung Transplant 14: 613-622.

[97] Stapleton DD, Mehra MR, Dumas D, Smart FW, Milani RV, et al. (1997) Lipid-lowering therapy and long-term survival in heart transplantation. Am J Cardiol 80: 802-805.

[98] Boissonnat P, Salen P, Guidollet J, Ferrera R, Dureau G, et al. (1994) The long-term effects of the lipid-lowering agent fenofibrate in hyperlipidemic heart transplant recipients. Transplantation 58: 245-247.

[99] Suchy D, Labuzek K, Stadnicki A, Okopien B Ezetimibe--a new approach in hypercholesterolemia management. Pharmacol Rep 63: 1335-1348.

[100] Yoon HE, Song JC, Hyoung BJ, Hwang HS, Lee SY, et al. (2009) The efficacy and safety of ezetimibe and low-dose simvastatin as a primary treatment for dyslipidemia in renal transplant recipients. Korean J Intern Med 24: 233-237.

[101] Lopez V, Gutierrez C, Gutierrez E, Sola E, Cabello M, et al. (2008) Treatment with ezetimibe in kidney transplant recipients with uncontrolled dyslipidemia. Transplant Proc 40: 2925-2926. 